\title{
Ultrasound evaluation of fetal gender at 12-14 weeks
}

\author{
Marek Lubuskya,b, Martina Studnickovaa , Ales Skrivanek ${ }^{a}$, Katherine Vomackovac, Martin Prochazka ${ }^{a}$
}

\begin{abstract}
Aims. The aim of this study was to assess the feasibility and accuracy of fetal gender assignment by transabdominal ultrasound at 12-14 weeks of gestation.

Methods. Fetal gender assessment was performed in 1222 singleton pregnancies. In all fetuses the crown-rump length (CRL) was measured and the genital area of the fetus was examined in the mid-sagittal plane. The result of ultrasound examination was compared to the phenotypic sex of the newborn after delivery.

Results. The feasibility as well as accuracy in determining gender increased with growing fetal CRL. At CRL $<50 \mathrm{~mm}$ (gestational age $<11+4$ ) the feasibility was $39.1 \%$ and accuracy $30.5 \%(40.9 \%$ in male gender vs $24.3 \%$ in female gender). At CRL 50-54.9 mm (gestational age $11+4$ to $12+0)$ the feasibility was $63.5 \%$ and accuracy $75.0 \%(89.1 \%$ in male gender vs $66.7 \%$ in female gender). At CRL 55-59.9 mm (gestational age $12+0$ to $12+2$ ) the feasibility was $90.5 \%$ and accuracy $96.6 \%$ (99.1\% in male gender vs $93.5 \%$ in female gender). At CRL $\geq 60 \mathrm{~mm}$ (gestational age $\geq 12+2$ ) the feasibility was $97.4 \%$ and accuracy $100.0 \%$ (100.0\% in male gender vs $100.0 \%$ in female gender).

Conclusions. Fetal gender may reliably be determined when $\mathrm{CRL} \geq 60 \mathrm{~mm}$ (gestational age $\geq 12+2$ ). Male gender may already be reliably determined when $C R L \geq 55 \mathrm{~mm}$ (gestational age $\geq 12+0$ ). If $C R L<50 \mathrm{~mm}$ (gestational age $<11+4$ ) the gender cannot be reliably predicted.
\end{abstract}

Key words: fetal gender, fetal sex, first trimester, ultrasonography

Received: August 27, 2011; Accepted with revision: February 14, 2012; Available online: April 19, 2012 http://dx.doi.org/10.5507/bp.2012.022

${ }^{a}$ Department of Obstetrics and Gynecology, University Hospital Olomouc, Czech Republic

${ }^{b}$ Department of Medical Genetics and Fetal Medicine, University Hospital Olomouc

'Department of Surgery I, University Hospital Olomouc

Corresponding author: Marek Lubusky, e-mail: marek@lubusky.com

\section{INTRODUCTION}

During screening for Down syndrome in the I. trimester of pregnancy, parameters with values dependent on fetal gender (fetal nuchal translucency measured by ultrasound, free $\beta$-hCG and PAPP-A levels in maternal serum) are evaluated when calculating "individual risk" of incidence of trisomy in the fetus ${ }^{1-4}$.

Reliable non-invasive determination of fetal gender in the monitored time period could enable modification of normal values of these parameters based on fetal gender and make the algorithm for calculating "individual risk" more accurate. A more accurate calculation of the "individual risk" of incidence of trisomy in the fetus could lead to a decrease in the number of invasive procedures (chorionic villus sampling, amniocentesis) indicated to determine the karyotype of the fetus and thus minimalize possible fetal complications associated with these examinations. Also, it would not be necessary to perform invasive procedures if there was suspicion of sex-linked genetic disease of the fetus ${ }^{5-7}$.

Information about fetal gender is currently not used in clinical practice for the correction of calculation of „individual risk“ for fetal trisomy. In contrast, if there is suspicion of sex-linked genetic diseases, reliable information about fetal gender already plays a significant role in current clinical practice.

To date, only a few studies regarding fetal gender as- signment in early pregnancy by ultrasound have been published, and these are usually of an older date and describe only a small sample of patients ${ }^{8-20}$.

The aim of this study was to assess the feasibility and accuracy of fetal gender assignment by transabdominal ultrasound at 12-14 weeks of gestation, during which combined screening for the most common fetal chromosomal anomalies is performed.

\section{MATERIALS AND METHODS}

Ultrasound examination aimed at determining fetal gender was performed during the first trimester of pregnancy at 12-14 weeks (CRL, 45-82.4 mm). All examinations were performed by one examiner (M.L.). From January 2005 to February 2010, a total of 1222 fetuses were examined, all were from a single pregnancy without established morphological or chromosomal abnormalities in the fetus or newborn. All the scans were performed transabdominally using $5-\mathrm{MHz}$ transducers (GE Voluson E8 Expert; GE Voluson 730 Expert, GE Healthcare Technologies, Zipf, Austria). The crown-rump length (CRL) was measured in all fetuses. The genital area of the fetus was examined in the mid-sagittal plane, in the neutral position of the fetus (without the presence of hyperflexion or hyperextension). When determining fetal gender, the method described by Efrat et al. ${ }^{13}$ was 
used. The angle between the genital tubercle axis and a horizontal line through the lumbosacral skin surface was measured. Angles $>30^{\circ}$ established the gender to be male (Fig. 1), if the axis of the genital tubercle ran parallel $\left(<10^{\circ}\right)$ or convergent to the horizontal line, gender was established as female (Fig. 2), if the angle was intermediate $\left(10-30^{\circ}\right)$ gender was not determined. The result of ultrasound examination was compared to the phenotypic sex of the newborn after delivery.

Statistical analysis was performed using the $\chi 2$ test, or Fisher's exact test when appropriate. Values of $P<0.05$ were considered statistically significant.

\section{RESULTS}

The possibility of determining fetal gender during ultrasound examination based on the crown-rump length (CRL) is presented in Table 1, 2. It was possible to establish gender in 1025 of a total of 1222 fetuses (84\%). In 197 fetuses $(16 \%)$ it was not possible to determine gender during ultrasound examination. The most common cause was an intermediate angle $\left(10-30^{\circ}\right)$ between genital tubercle axis and the horizontal line (78\%), followed by unfavorable fetal position (12\%) and maternal habitus (10\%). In 51 of 1025 fetuses $(5 \%)$ it was not possible to perform a comparison of gender assignment by ultrasound examination with phenotypic sex of the newborn after delivery. In the remaining 974 fetuses, gender was correctly established in $92.5 \%$ of cases (901/974), male gender in $96.3 \%$ (471/489), female gender in 88.7\% (430/485) (Table 3).

The feasibility and accuracy in determining gender during ultrasound examination increased with growing crown-rump length (CRL) of the fetus (Table 2, 3, 4, 5, $6)$. The difference between male and female gender was not statistically significant.

The feasibility of gender determination during ultrasound examination was 39\% at CRL $45-49.9 \mathrm{~mm}, 64 \%$ at CRL 50-54.9 mm, 90\% at CRL 55-59.9 $\mathrm{mm}$ and $97.4 \%$ at CRL 60-82.4 $\mathrm{mm}$. The difference was statistically significant ( $P=0.012$ for CRL 45-49.9 mm vs. CRL 50-54.9 $\mathrm{mm}, P=0.021$ for CRL 50-54.9 mm vs. CRL 55-59.9 mm, and $P<0.0001$ for CRL 45-54.9 mm vs. CRL 55-82.4 $\mathrm{mm}$ )

The accuracy in determining male gender was $41 \%$ at CRL 45-49.9 mm, 89\% at CRL 50-54.9 mm, 99\% at CRL 55-59.9 $\mathrm{mm}$ and 100\% at CRL 60-82.4 $\mathrm{mm}$. The difference was statistically significant $(P=0.023$ for $C R L$ 45-49.9 mm vs. CRL 50-82.4 mm).

The accuracy in determining female gender was $24 \%$ at CRL $45-49.9 \mathrm{~mm}, 67 \%$ at CRL $50-54.9 \mathrm{~mm}, 94 \%$ at CRL 55-59.9 $\mathrm{mm}$ and $100 \%$ at CRL $60-82.4 \mathrm{~mm}$. The difference was statistically significant $(P=0.014$ for $C R L$ 45-49.9 mm vs. CRL 50-54.9 mm, $P=0.00013$ for CRL 45-49.9 mm vs. CRL 50-82.4 mm, $P=0.00036$ for CRL 45-54.9 mm vs. CRL 55-82.4 mm, and $P=0.015$ for CRL 45-59.9 mm vs. CRL 60-82.4 mm).

At CRL $<50 \mathrm{~mm}$ (gestational age $<11+4$ ) feasibility was $39.1 \%$ and accuracy $30.5 \%$ (40.9\% in male gender vs $24.3 \%$ in female gender). At CRL 50-54.9 mm (gestational age $11+4$ to $12+0$ ) the feasibility was $63.5 \%$ and accuracy $75.0 \%$ (89.1\% in male gender vs $66.7 \%$ in female gender). At CRL 55-59.9 mm (gestational age 12+0 to $12+2$ ) the feasibility was $90.5 \%$ and accuracy $96.6 \%$ (99.1\% in male gender vs $93.5 \%$ in female gender). At CRL $\geq 60 \mathrm{~mm}$ (gestational age $\geq 12+2$ ) the feasibility was $97.4 \%$ and accuracy $100.0 \%$ (100.0\% in male gender vs $100.0 \%$ in female gender).

\section{DISCUSSION}

According to our results, it was possible to reliably determine the fetal gender by transabdominal ultrasound (feasibility $97.4 \%$, accuracy $100 \%$ ) at CRL $\geq 60 \mathrm{~mm}$ (gestational age $\geq 12+2$ ). At $\mathrm{CRL} \geq 55 \mathrm{~mm}$ (gestational age $\geq 12+0$ ) the feasibility was $95.5 \%$ and accuracy $99.1 \%$ (99.8\% in male gender vs $98.4 \%$ in female gender). At

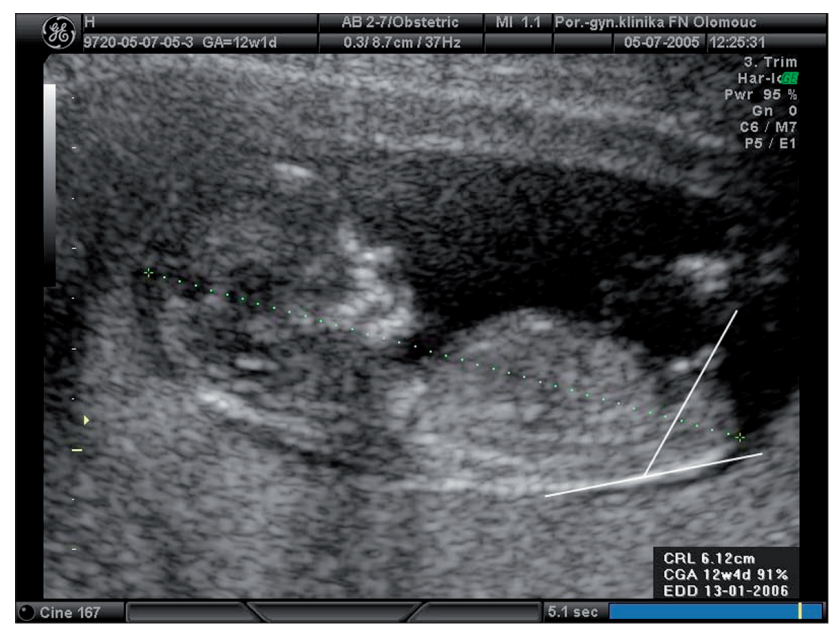

Fig. 1. Ultrasound examination established gender to be male if the angle between the genital tubercle axis and a horizontal line through the lumbosacral skin surface was $>30^{\circ}$.

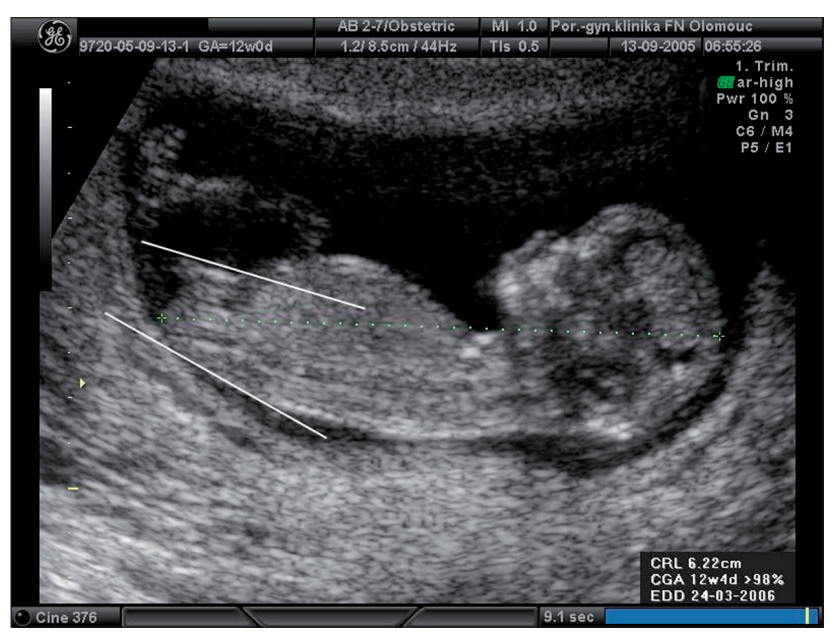

Fig. 2. Ultrasound examination established gender to be female if the axis of the genital tubercle ran parallel $\left(<10^{\circ}\right)$ or convergent to the horizontal line. 
Table 1. Gender identification at ultrasound examination according to crown-rump length (CRL).

\begin{tabular}{|c|c|c|c|c|c|c|}
\hline \multirow{2}{*}{$\begin{array}{l}\text { CRL } \\
(\mathrm{mm})\end{array}$} & \multirow{2}{*}{$\begin{array}{c}\text { Gestational age } \\
\text { (weeks) }\end{array}$} & \multirow{2}{*}{$\begin{array}{l}\text { Patients } \\
\text { (n) }\end{array}$} & \multicolumn{2}{|c|}{$\begin{array}{l}\text { Gender indetified } \\
\text { by ultrasound }\end{array}$} & \multirow{2}{*}{$\begin{array}{l}\text { Gender } \\
\text { verified } \\
\text { (n) }\end{array}$} & \multirow{2}{*}{$\begin{array}{l}\text { Lost to } \\
\text { follow-up } \\
\text { (n) }\end{array}$} \\
\hline & & & (n) & $(\%)$ & & \\
\hline $45.0-49.9$ & $11+1$ to $11+4$ & 156 & 61 & 39 & 59 & 2 \\
\hline $50.0-54.9$ & $11+4$ to $12+0$ & 170 & 108 & 64 & 100 & 8 \\
\hline $55.0-59.9$ & $12+0$ to $12+2$ & 242 & 219 & 90 & 208 & 11 \\
\hline $60.0-64.9$ & $12+2$ to $12+5$ & 291 & 283 & 97 & 268 & 15 \\
\hline $65.0-69.9$ & $12+5$ to $13+1$ & 238 & 232 & 97 & 222 & 10 \\
\hline $70.0-74.9$ & $13+1$ to $13+3$ & 58 & 57 & 98 & 56 & 1 \\
\hline $75.0-79.9$ & $13+3$ to $13+5$ & 43 & 42 & 98 & 41 & 1 \\
\hline $80.0-82.4$ & $13+5$ to $13+6$ & 24 & 23 & 96 & 20 & 3 \\
\hline Total & & 1222 & 1025 & 84 & 974 & 51 \\
\hline
\end{tabular}

Table 2. Gender feasibility by ultrasound according to crown-rump lenght (CRL).

\begin{tabular}{|c|c|c|c|c|c|c|c|}
\hline $\begin{array}{l}\text { CRL } \\
(\mathrm{mm})\end{array}$ & $\begin{array}{c}\text { Gestational age } \\
\text { (weeks) }\end{array}$ & $\begin{array}{c}\text { Feasibility } \\
(\%)\end{array}$ & & & & & \\
\hline $45.0-49.9$ & $11+1$ to $11+4$ & 39,1 & \multirow{2}{*}{51.8} & \multirow{8}{*}{83.9} & & & \\
\hline $50.0-54.9$ & $11+4$ to $12+0$ & 63,5 & & & \multirow{7}{*}{90.4} & & \\
\hline $55.0-59.9$ & $12+0$ to $12+2$ & 90,5 & \multirow{3}{*}{95.2} & & & \multirow{6}{*}{95.5} & \\
\hline $60.0-64.9$ & $12+2$ to $12+5$ & 97,3 & & & & & \multirow{5}{*}{97.4} \\
\hline $65.0-69.9$ & $12+5$ to $13+1$ & 97,5 & & & & & \\
\hline $70.0-74.9$ & $13+1$ to $13+3$ & 98,3 & \multirow{3}{*}{97.6} & & & & \\
\hline $75.0-79.9$ & $13+3$ to $13+5$ & 97,7 & & & & & \\
\hline $80.0-82.4$ & $13+5$ to $13+6$ & 95,8 & & & & & \\
\hline
\end{tabular}

Table 3. Accuracy of sonographic fetal gender assignment according to crown-rump length.

\begin{tabular}{cccccccc}
\hline $\begin{array}{c}\text { CRL } \\
(\mathrm{mm})\end{array}$ & $\begin{array}{c}\text { Gestational age } \\
(\text { weeks })\end{array}$ & \multicolumn{2}{c}{ Total accuracy } & \multicolumn{2}{c}{ Male accuracy } & \multicolumn{2}{c}{ Female accuracy } \\
\hline $45.0-49.9$ & $11+1$ to $11+4$ & $18 / 59$ & 31 & $9 / 22$ & 41 & $9 / 37$ & 24 \\
$50.0-54.9$ & $11+4$ to $12+0$ & $75 / 100$ & 75 & $33 / 37$ & 89 & $42 / 63$ & 67 \\
\hline $55.0-59.9$ & $12+0$ to $12+2$ & $201 / 208$ & 97 & $114 / 115$ & 99 & $87 / 93$ & 94 \\
$60.0-64.9$ & $12+2$ to $12+5$ & $268 / 268$ & 100 & $135 / 135$ & 100 & $133 / 133$ & 100 \\
$65.0-69.9$ & $12+5$ to $13+1$ & $222 / 222$ & 100 & $121 / 121$ & 100 & $101 / 101$ & 100 \\
\hline $70.0-74.9$ & $13+1$ to $13+3$ & $56 / 56$ & 100 & $29 / 29$ & 100 & $27 / 27$ & 100 \\
$75.0-79.9$ & $13+3$ to $13+5$ & $41 / 41$ & 100 & $18 / 18$ & 100 & $23 / 23$ & 100 \\
$80.0-82.4$ & $13+5$ to $13+6$ & $20 / 20$ & 100 & $12 / 12$ & 100 & $8 / 8$ & 100 \\
\hline Total & & $901 / 974$ & 93 & $471 / 489$ & 96 & $430 / 485$ & 89 \\
\hline
\end{tabular}


Table 4. Total accuracy of sonographic fetal gender assignment according to crown-rump length.

\begin{tabular}{|c|c|c|c|c|c|c|c|}
\hline $\begin{array}{l}\text { CRL } \\
(\mathrm{mm})\end{array}$ & $\begin{array}{l}\text { Gestational age } \\
\text { (weeks) }\end{array}$ & Tot & acy & & & & \\
\hline $45.0-49.9$ & $11+1$ to $11+4$ & 30.5 & \multirow{2}{*}{58.5} & \multirow{8}{*}{92.5} & & & \\
\hline $50.0-54.9$ & $11+4$ to $12+0$ & 75 & & & \multirow{7}{*}{96.5} & & \\
\hline $55.0-59.9$ & $12+0$ to $12+2$ & 96.6 & \multirow{3}{*}{99} & & & \multirow{6}{*}{99.1} & \\
\hline $60.0-64.9$ & $12+2$ to $12+5$ & 100 & & & & & \multirow{5}{*}{100} \\
\hline $65.0-69.9$ & $12+5$ to $13+1$ & 100 & & & & & \\
\hline $70.0-74.9$ & $13+1$ to $13+3$ & 100 & \multirow{3}{*}{100} & & & & \\
\hline $75.0-79.9$ & $13+3$ to $13+5$ & 100 & & & & & \\
\hline $80.0-82.4$ & $13+5$ to $13+6$ & 100 & & & & & \\
\hline
\end{tabular}

Table 5. Male accuracy of sonographic fetal gender assignment accoridng to crown-rump length.

\begin{tabular}{|c|c|c|c|c|c|c|c|}
\hline $\begin{array}{l}\text { CRL } \\
(\mathrm{mm})\end{array}$ & $\begin{array}{l}\text { Gestational age } \\
\text { (weeks) }\end{array}$ & & & & & & \\
\hline $45.0-49.9$ & $11+1$ to $11+4$ & 40.9 & \multirow{2}{*}{71.2} & \multirow{8}{*}{96.3} & & & \\
\hline $50.0-54.9$ & $11+4$ to $12+0$ & 89.1 & & & \multirow{7}{*}{98.9} & & \\
\hline $55.0-59.9$ & $12+0$ to $12+2$ & 99.1 & \multirow{3}{*}{99.7} & & & \multirow{6}{*}{99.8} & \\
\hline $60.0-64.9$ & $12+2$ to $12+5$ & 100 & & & & & \multirow{5}{*}{100} \\
\hline $65.0-69.9$ & $12+5$ to $13+1$ & 100 & & & & & \\
\hline $70.0-74.9$ & $13+1$ to $13+3$ & 100 & \multirow{3}{*}{100} & & & & \\
\hline $75.0-79.9$ & $13+3$ to $13+5$ & 100 & & & & & \\
\hline $80.0-82.4$ & $13+5$ to $13+6$ & 100 & & & & & \\
\hline
\end{tabular}

Table 6. Female accuracy of sonographic fetal gender assignment accoridng to crown-rump length.

\begin{tabular}{|c|c|c|c|c|c|c|c|}
\hline $\begin{array}{l}\text { CRL } \\
(\mathrm{mm})\end{array}$ & $\begin{array}{l}\text { Gestational age } \\
\text { (weeks) }\end{array}$ & Fema & Iracy & & & & \\
\hline $45.0-49.9$ & $11+1$ to $11+4$ & 24.3 & \multirow{2}{*}{51} & \multirow{8}{*}{88.7} & & & \\
\hline $50.0-54.9$ & $11+4$ to $12+0$ & 66.7 & & & \multirow{7}{*}{94} & & \\
\hline $55.0-59.9$ & $12+0$ to $12+2$ & 93.5 & \multirow{3}{*}{98.2} & & & \multirow{6}{*}{98.4} & \\
\hline $60.0-64.9$ & $12+2$ to $12+5$ & 100 & & & & & \multirow{5}{*}{100} \\
\hline $65.0-69.9$ & $12+5$ to $13+1$ & 100 & & & & & \\
\hline $70.0-74.9$ & $13+1$ to $13+3$ & 100 & \multirow{3}{*}{100} & & & & \\
\hline $75.0-79.9$ & $13+3$ to $13+5$ & 100 & & & & & \\
\hline $80.0-82.4$ & $13+5$ to $13+6$ & 100 & & & & & \\
\hline
\end{tabular}


$\mathrm{CRL} \geq 50 \mathrm{~mm}$ (gestational age $\geq 11+4$ ) the feasibility was $90.4 \%$ and accuracy $96.5 \%$ (98.9\% in male gender vs $94.0 \%$ in female gender). At CRL $\geq 45 \mathrm{~mm}$ (gestational age $\geq 11+1$ ) the feasibility was $83.9 \%$ and accuracy $92.5 \%$ ( $96 \%$ in male gender vs $88.7 \%$ in female gender).

Efrat et al. ${ }^{13}$ describe the feasibility of determining fetal gender using transabdominal ultrasound as $92.6 \%$ $(\mathrm{CRL} \geq 55.4 \mathrm{~mm} ; \mathrm{n}=656)$, Chelli et al. ${ }^{10}$ 89.7\% (CRL $\geq 45 \mathrm{~mm} ; \mathrm{n}=312$ ), Hsiao et al. ${ }^{11}$ report the feasibility as 88.9\% (CRL $\geq 45 \mathrm{~mm} ; \mathrm{n}=496)$ and $96 \%$ (CRL $\geq 57 \mathrm{~mm}$; $\mathrm{n}=400$ ), Mazza et al. ${ }^{14}$ 87.5\% (BPD 18-29 mm; $\mathrm{n}=385$ ). In the last two studies, however, the same method was not used to determine gender and in the last study a different biometric parameter was used (BPD; biparietal diameter of the head). It is also difficult to compare the results due to the small sample size of patients as well as the improved imaging of new ultrasound devices.

Efrat et al. ${ }^{13}$ present the accuracy of determining fetal gender to be $98.5 \%$ (CRL $\geq 55.4 \mathrm{~mm}$ ), $99.6 \%$ in male gender vs $97.4 \%$ in female gender. Chelli et al. ${ }^{10}$ describe at $\mathrm{CRL} \geq 45 \mathrm{~mm}$ an accuracy of $85.7 \%$ (in male gender $87.9 \%$ vs $83.3 \%$ in female gender). Hsiao et al. ${ }^{11}$ report an accuracy of $91.8 \%$ (CRL $\geq 45 \mathrm{~mm}$ ), $92.5 \%$ in male gender vs $91.2 \%$ in female gender. Mazza et al. ${ }^{14}$ at BPD $18-29$ mm describe an acucuracy of $87.5 \%$ (male gender $91.5 \%$ vs $95.9 \%$ female gender) and at $\mathrm{BPD} \geq 23 \mathrm{~mm}$ report an accuracy of $100 \%$.

At CRL $<50 \mathrm{~mm}$ (gestational age < 11+4) fetal gender assignment by transabdominal ultrasound in our patient set was possible in only $39 \%$ of fetuses $(61 / 156)$. In most cases gender was determined to be female (63\%). The assignment accuracy was in indirect proportion between the sexes, male gender was successfully determined in $41 \%$ of cases (9/22) and female in only $24 \%$ of cases (9/37). Therefore in total, reliable gender assignment was possible in only $11.7 \%(18 / 154)$ of the examined fetuses. Efrat et al. ${ }^{12}$ at CRL $43.4-55.3 \mathrm{~mm}$ present reliability of gender assignment to be $92.5 \%$ (37/40) and accuracy to be $70.2 \%(26 / 37), 44.4 \%$ in male gender assignment $(8 / 18)$ vs $94.7 \%$ in female gender assignment (18/19). However, this study used a different method for determining fetal gender and a different CRL was evaluated. At a similar CRL of 45-54.9 $\mathrm{mm}$ the feasibility of gender determination in our set was $51.8 \%(169 / 326)$ and accuracy was $58.5 \%$ (93/159), 71.2\% in male gender assignment (42/59) vs $51.0 \%$ in female gender assignment $(51 / 100)$.

Pedreira et al. ${ }^{21}$ described a change in the orientation of the genital tubercle during examination (CRL 44.7$72.6 \mathrm{~mm}$ ) on a set of 11 fetuses ( 6 fetuses of male gender and 5 fetuses of female gender). Determination of fetal gender in the first trimester of pregnancy by transabdominal ultrasound necessitates considerable erudition of the examiner and a sufficient timeframe for the examination, because the most difficult as well as most important is the imaging of the fetus in the required reference plane. According to our results, at CRL $<50 \mathrm{~mm}$ (gestational age $<11+4$ ) the fetal gender cannot be reliably predicted using this method.
Cowans et al. ${ }^{1}$ demonstrated the significant influence of fetal gender on values of nuchal translucency (delta NT) and level of free $B-h C G$ and PAPP-A in maternal serum during screening for chromosomal aneuploidies in the first trimester on a set of 56024 normal singleton pregnancies and in 722 pregnancies where the fetus had trisomy 21. Normal female fetuses had levels of nuchal translucency (delta NT) which were $9.4 \%$ lower, and maternal serum levels of free $\mathrm{B}-\mathrm{hCG}$ and PAPP-A were higher (by $14.7 \%$ and $6.3 \%$ respectively) compared to fetuses of male gender. Female fetuses with trisomy 21 had $12 \%$ lower values of nuchal translucency (delta NT) and higher levels of free $\mathrm{B}-\mathrm{hCG}$ (by 20.8\%) and PAPP-A (by $5.7 \%$ ). Larsen et al. ${ }^{3}$ describe higher levels of free $B-\mathrm{hCG}$ (by $15 \%$ ) as well as PAPP-A (by $7 \%$ ) in maternal serum in cases of female fetuses in a set of 2637 normal single pregnancies. Lam et al. ${ }^{2}$ on a set of 12189 pregnancies between week 10-14 presented 5\% lower values of nuchal translucency (delta NT) in fetuses of female gender. Reliable determination of fetal gender by transabdominal ultrasound in week 12-14 of gestation could serve as an additional marker to allow for more accurate calculation of the individual risk of incidence of trisomy 21 in the fetus.

Fetal gender may also be determined non-invasively in the first trimester by analyzing free fetal DNA obtained from the plasma of maternal peripheral blood. The method allows assignment of genotypic sex of the fetus and sensitivity and specificity of this method is nearly $100 \%$ (ref. $^{5}$ ). During ultrasound examination, only the phenotypic sex of the fetus may be assessed, which may differ from genotypic sex (testicular feminization, severe hypospadia, etc.). However, ultrasound examination is less invasive, less expensive and easily feasible. The possibility of reliably and non-invasively determining fetal gender already in the first trimester, however, incurs the risk of misuse of fetal gender selection for non-medical purposes.

\section{CONCLUSIONS}

Fetal gender may reliably be determined by transabdominal ultrasound when $\mathrm{CRL} \geq 60 \mathrm{~mm}$ (gestational age $\geq 12+2$ ). Male gender may already be reliably determined when CRL $\geq 55 \mathrm{~mm}$ (gestational age $\geq 12+0$ ). If CRL < $50 \mathrm{~mm}$ (gestational age < 11+4) gender cannot be reliably predicted. It is always necessary to take into account the maternal habitus, the position of the fetus and the imaging possibilities of the ultrasound device. The experience and erudition of the examiner are very important.

\section{ABBREVATIONS}

BPD, Biparietal diameter; CRL, Crown-rump length; hCG, Human chorionic gonadotropin; NT, Nuchal translucency; PAPP-A, Pregnancy associated plasma protein - A. 


\section{ACKNOWLEDGEMENTS}

Supported by the grants from the Ministry of Health of the Czech Republic IGA NS 10311-3/2009, NT 11004-3/2010, NT 12225-4/2011.

\section{REFERENCES}

1. Cowans NJ, Stamatopoulou A, Maiz N, Spencer K, Nicolaides KH. The impact of fetal gender on first trimester nuchal translucency and maternal serum free beta-hCG and PAPP-A MoM in normal and trisomy 21 pregnancies. Prenat Diagn 2009;29:578-81.

2. Lam YH, Tang MH, Lee CP, Sin SY, Tang R, Wong HS, Wong SF. The effect of fetal gender on nuchal translucency at 10-14 weeks of gestation. Prenat Diagn 2001;21:627-9.

3. Larsen SO, Wøjdemann KR, Shalmi AC, Sundberg K, Christianses M, Tabor A. Gender impact on first trimester markers in Down syndrome screening. Prenat Diagn 2002;22:1207-8.

4. Spencer K, Ong CY, Liao AW, Papademetriou D, Nicolaides KH. The influence of fetal sex in screening for trisomy 21 by fetal nuchal translucency, maternal serum free beta-hCG and PAPP-A at 10-14 weeks of gestation. Prenat Diagn 2000;20:673-5.

5. Finning KM, Chitty LS. Non-invasive fetal sex determination: impact on clinical practice. Semin Fetal Neonatal Med 2008;13:69-75.

6. Hyett JA, Gardener G, Stojilkovic-Mikic T, Finning KM, Martin PG, Rodeck $\mathrm{CH}$, Chitty LS. Reduction in diagnostic and therapeutic interventions by non-invasive determination of fetal sex in early pregnancy. Prenat Diagn 2005;25:1111-6.

7. Mazza V, Falcinelli C, Percesepe A, Paganelli S, Volpe A, Forabosco A Non-invasive first trimester fetal gender assignment in pregnancies at risk for X-linked recessive diseases. Prenat Diagn 2002;22:919-24.

8. Benoit B. Early fetal gender determination [opinion]. Utrasound Obstet Gynecol 1999;13:299-300.

9. Bronsthein M, Rottem S, Yoffe N, Blumenfeld Z, Brandes JM. Early determination of fetal sex using transvaginal sonography: technique and pitfalls. J Clin Ultrasound 1990;18:302-6.
10. Chelli D, Methni A, Dimassi K, Boudaya F, Sfar E, Zouaoui B, Chelli H, Chennoufi MB. Fetal sex assignment by first trimester ultrasound: a Tunisian experience. Prenat Diagn 2009;29:1145-8.

11. Hsiao $\mathrm{CH}$, Wang $\mathrm{HC}$, Hsieh CF, Hsu JJ. Fetal gender screening by ultrasound at 11 to $13+6$ weeks. Acta Obstet Gynecol Scand 2008;87:813.

12. Efrat Z, Akinfenwa OO, Nicolaides KH. First-trimester determination of fetal gender by ultrasound. Ultrasound Obstet Gynecol 1999;13:305-7.

13. Efrat Z, Perri T, Ramati E, Tugendreich D, Meizner I. Fetal gender assignement by first-trimester ultrasound. Ultrasound Obstet Gynecol 2006;27:619-21.

14. Mazza V, Contu G, Falcinelli C, Battafarano S, Cagnacci A, Vito G, Forabosco A, Volpe A. Biometrical threshold of biparietal diameter for certain fetal sex assignment by ultrasound. Ultrasound Obstet Gynecol 1999;13:308-11.

15. Mazza V, Falcinelli C, Paganelli S, Contu G, Mantuano SM, Battafarano SD, Forabosco A, Volpe A. Sonographic early fetal gender assignment: a longitudinal study in pregnancies after in vitro fertilization. Ultrasound Obstet Gynecol 2001;17:513-6.

16. Mazza V, Di Monte I, Pati M, Contu G, Ottolenghi C, Forabosco A Volpe A. Sonographic biometrical range of external genitalia differentiation in the first trimester of pregnancy: analysis of 2593 cases. Prenat Diagn 2004;24:677-84.

17. Michailidis GD, Papageorgiou P, Morris RW, Economides DL. The use of three-dimensional ultrasound for fetal gender determination in the first trimester. Br J Radiol 2003;76:448-51.

18. Mielke G, Kiesel L, Backsch C, Erz W, Gonser M. Fetal sex determination by high resolution ultrasound in early pregnancy. Eur J Ultrasound 1998;7:109-14.

19. Pedreira DA. In search for the 'third point' [comment]. Ultrasound Obstet Gynecol 2000;15:262-3.

20. Whitlow BJ, Lazanakis MS, Economides DL. The sonographic identification of fetal gender from 11 to 14 weeks of gestation. Ultrasound Obstet Gynecol 1999;13:301-4.

21. Pedreira DA, Yamasaki A, Czeresnia CE. Fetal Phallus 'errection' interfering with the sonographic determination of fetal gender in the first trimester. Ultrasound Obstet Gynecol 2001;18:402-4. 